\title{
Silêncio atômico: política, violência, exceção após Hiroshima e Nagasaki
}

\author{
Atomic Silence: politics, violence, exception after \\ Hiroshima and Nagasaki
}

Izadora Zubek*

\section{Resumo}

O artigo analisa as consequências políticas de Hiroshima e Nagasaki. O ponto de partida é o pensamento de Hannah Arendt. A autora afirma que a violência silencia a política, caracterizada pelo diálogo. A metáfora do silêncio se torna o fio condutor de uma reflexão sobre o significado das armas nucleares na política mundial. Os discursos dominantes sobre a bomba atômica são examinados e criticados. 0 artigo ilumina os efeitos produtivos da bomba e tenta resgatar a "fala" dos escombros nucleares. As histórias dos sobreviventes contribuem para a formação de uma perspectiva crítica que desestabiliza os limites temporais da violência bélica.

Palavras-Chave: Armas Nucleares; Política; Violência; Exceção; Teoria Crítica; Hibakusha; Silêncio

\section{Abstract}

The article analyzes the political consequences of Hiroshima and Nagasaki. The starting point is the thought of Hannah Arendt. The author states that violence silences politics, characterized by dialogue. The metaphor of silence paves the way for a reflection on the significance of nuclear weapons in world politics. The dominant discourses on nuclear weapons are examined and criticized. The article illuminates the productive effects of the atomic bomb and attempts to rescue "speech" from the nuclear debris. The stories of survivors lead to a critical perspective that destabilizes the temporal limits of wartime violence.

Keywords: Nuclear Weapons; Politics; Violence; Exception; Critical Theory; Hibakusha; Silence

\footnotetext{
* Mestranda em Relações Internacionais pela Pontifícia Universidade Católica do Rio de Janeiro (IRI/PUC-Rio). Graduada em Ciências Políticas e Sociais pela Université Paris II Panthéon-Assas. Bolsista Nota 10 da FAPERJ. Conduziu pesquisa em Hiroshima, onde encontrou sobreviventes do bombardeio atômico e presenciou as comemorações de aniversário, em agosto de 2015. E-mail: izadora.zubek@gmail.com
} 
Impossible to talk about Hiroshima. All one can do is talk about the impossibility of talking about Hiroshima. - Marguerite Duras, Hiroshima Mon Amour

\title{
1 Introdução: Um Aniversário Lúgubre
}

Nos dias 6 e 9 de agosto, um aniversário lúgubre é comemorado. Em 2015, os bombardeios atômicos de Hiroshima e Nagasaki completam setenta anos. Uma multidão se reúne para homenagear os mortos e afirmar o repúdio às armas nucleares. Lanternas coloridas, com mensagens de paz, flutuam sobre o rio Ota. Um silêncio solene é respeitado, em memória de outros silêncios impostos pela bomba atômica.

Houve o silêncio abismado diante de uma nova tecnologia bélica. Os efeitos da bomba desconcertaram os contemporâneos. Wilfred Burchett foi um dos primeiros jornalistas a se deparar com as ruinas de Hiroshima, no dia 2 de setembro de 1945. Atônito, ele escreve que a cidade não parecia bombardeada mas completamente esmagada e aniquilada por um rolo compressor. Milhares de pessoas desapareceram, sem deixar vestígios - nem sequer cinzas. Nos escombros nucleares, Burchett foi confrontado com o que ele qualificou de "a mais terrivel e assustadora desolação em quatro anos de guerra" (BURCHETT; SHIMMIN, 2007, p. 2).

Houve então o silêncio doloroso das vítimas que, segundo Kenzaburo Oe (2012, p. 260, tradução nossa), era "o mais cruel, o mais absoluto." O escritor cita o testemunho de uma sobrevivente:

\begin{abstract}
Era impossivel distinguir os homens das mulheres, os jovens dos velhos. Eles estavam sentados em fileira, quase nus, e todos tinham os rostos e os corpos inchados e amarronzados [...] Alguns já estavam cegos. Sobre os joelhos de alguém, havia um bebê e, quando vi a pele de suas costas que pendia em frangalhos, como a de uma nêspera estragada e escurecida, não pude deixar de desviar o olhar. Todos permaneciam imóveis, petrificados em um silêncio lúgubre, de tal modo que não dava para saber se eles estavam vivos ou mortos. (apud OE, 2012, p. 260-261, tradução nossa)
\end{abstract}

A violência da catástrofe atômica é tão atroz e insidiosa, tão imensa e inaudita, que ela silencia todos ao seu redor. Hannah Arendt (1990, p. 18) evidencia que, onde a violência absoluta impera, tudo e todos devem permanecer calados. A violência da bomba corrói a política que, de acordo com a autora, decorre da fala. Influenciada por Aristóteles, Arendt destaca que a violência é oposta ao diálogo, à persuasão, à linguagem que permite distinguir o justo do injusto. E é, justamente, a articulação dessa linguagem (o logos) que faz do homem um animal político (ARISTÓTELES, 1988, p. 51). Recorreremos, ao longo do artigo, a uma definição ampla da política, como modo de agir e compartilhar o mundo, e não apenas como um exercício do poder. Essa definição é inspirada pela filosofia de Jacques Rancière (2011).

\footnotetext{
1 Depois da capitulação japonesa, os Estados-Unidos emitiram acreditações para centenas de jornalistas a fim de cobrir a vitória. Burchett aproveitou a ocasião para se esgueirar e visitar Hiroshima. Ele chegou na cidade antes que o General MacArthur enviasse os jornalistas oficiais do Exército americano. Sua reportagem é considerada a primeira reportagem independente sobre os resultados do ataque nuclear (BURCHETT; SHIMMIN, 2007, p. 1).
} 
A violência atômica ameaça a política e desumaniza suas vítimas. Privadas da fala, ou seja, do atributo inerente ao humano, as vítimas se veem extirpadas de sua dignidade. Esquecidas em leitos de hospital, ausentes do espaço público, é como se elas nunca tivessem existido. É, portanto, vital que nos dediquemos a resgatar a fala: a pensar e a discutir a violência nuclear. É preciso investigar o silêncio, "falar sobre a impossibilidade de falar sobre Hiroshima" (DURAS, 1961, p. 9) para politizar a memória dos bombardeios atômicos. O que podemos falar sobre o uso da violência bélica após Hiroshima e Nagasaki? 0 artigo adota uma abordagem heterodoxa a fim de explorar as consequências políticas e éticas das armas nucleares. 0 método utilizado privilegia a análise dos discursos que informaram as percepções sobre a bomba atômica. Os discursos dominantes são confrontados com as narrativas dos sobreviventes. As histórias das vítimas de Hiroshima e Nagasaki contribuem para a formação de uma perspectiva crítica.

Em um primeiro momento, examinaremos o que foi dito sobre as armas nucleares. Durante a Cuerra Fria, a voz da razão (estratégica) se fez ouvir e a doutrina da dissuasão nuclear se estabeleceu. Paradoxalmente, a bomba foi considerada como um instrumento de paz. Ela era tão absurdamente violenta que ela tornava a guerra irracional. O realismo ditava esse discurso. Nina Tannenwald (2007) apresenta um argumento dissonante. Ela enfatiza o apelo das normas. Além da razão, foi a emergência de um "tabu nuclear" que fez de Hiroshima e Nagasaki eventos únicos. Não obstante, veremos como as normas se diluem na exceção que, segundo Carl Schmitt, é decidida pelo soberano. Em seguida, analisaremos os efeitos produtivos das armas nucleares na ordem internacional, criticando a visão de Tannenwald que acentua apenas as restrições ao uso. A violência "potencial" das armas nucleares é um recurso de poder que exacerba a desigualdade entre os Estados. Ademais, a bomba atômica, ao evocar imagens apocalípticas, cativa o imaginário político. Sua violência atinge proporções divinas e, deste modo, fortalece a fé no soberano. Finalmente, tentaremos nos voltar para os silenciosos, para os sobreviventes de Hiroshima e Nagasaki. À luz de suas experiências, refletiremos sobre a política depois da bomba e sobre os limites temporais da violência bélica.

\section{Discursos e Dissonâncias sobre as Armas Nucleares}

\subsection{A Voz da Razão Estratégica: Dissuasão e Paz Armada}

O historiador Akira Iriye (1981, p. 264) constata que, na manhã do dia 6 de agosto de 1945, a guerra como um fenômeno convencional chegou ao fim. Hiroshima modificou profundamente as relações internacionais. Depois de 1945, as armas nucleares passaram a reger a política externa e os pressupostos estratégicos das grandes potências. A guerra futura começou a ser visualizada como um conflito nuclear: não como um desvio temporário da norma, mas como o fim de toda ordem internacional e doméstica (IRIYE, 1981, p. 266). Quando a União Soviética obteve a bomba, seguida por outros países, um equilíbrio do terror se firmou. Além disso, a bomba termonuclear foi inventada, ampliando sensivelmente a capacidade de aniquilação dos Estados. 
A violência dessas novas armas é tamanha que elas colocam em risco o sistema, e o planeta, como um todo. Robert Jervis (1989, p. 119) salienta que ninguém poderia vencer uma guerra nuclear total e que seus resultados seriam calamitosos, fazendo com que a civilização retrocedesse séculos. Na doutrina da dissuasão, a ameaça latente basta para alcançar objetivos políticos. A violência "potencial" é apreciada como um instrumento de poder. De inspiração clausewitziana, a doutrina almeja controlar, racionalmente, os riscos ligados à propagação de armas nucleares. Deste modo, durante a Guerra Fria, o arsenal nuclear garantia a "paz" entre os "grandes". A prudência sustentava a ordem bipolar. Raymond Aron (1976, p. 183, tradução nossa) resumiu o paradoxo da época: "é a possibilidade da violência ilimitada que, sem mesmo que a ameaça seja proferida, restringe a violência efetiva". Stephen Cimbala (2005, p. 94) acrescenta que as armas nucleares pareciam ter tornado a guerra improvável, senão impossível, entre líderes "racionais" e Estados "desenvolvidos".

Depois da Guerra Fria, alguns neorrealistas como Kenneth Waltz (com SAGAN, 1995) continuaram a defender o papel vantajoso das armas nucleares na política mundial. Na década de 1990, Waltz certifica que a proliferação nuclear deve ser encorajada (com SAGAN, 1995, p. 45). 0 autor alega que as armas nucleares diminuem a intensidade e a frequência de conflitos entre seus possessores. Ademais, elas fazem com que os Estados se sintam mais seguros - o que é fundamental para a estabilidade de um sistema anárquico, regido pela lógica da autoajuda. Waltz também pressupõe a racionalidade e a prudência dos atores. A alternativa para a proliferação nuclear seria uma corrida armamentista ruinosa que exacerbaria o perigo de guerras convencionais. (SAGAN; WALTZ, 1995, p. 37). De certa forma, as armas nucleares, cujo uso é demasiado temerário, provocariam menos destruição do que as armas convencionais.

Os argumentos realistas que pregam a dissuasão, e até a proliferação nuclear, ignoram as preocupações morais levantadas pela bomba. Waltz se contenta em avaliar custos sem mencionar as consequências humanas. Esse discurso é criticado por Anthony Burke (2007). O autor cita J. Robert Oppenheimer, líder civil do Projeto Manhattan e um dos inventores da bomba atômica. Em uma palestra na Universidade de Porto Rico, Oppenheimer questionou os limites éticos da estratégia nuclear:

What are we to make of a civilization which has always thought of ethical questions as quite essential in human life, and which has always had a deep, articulate, fervent conviction, probably never a majority conviction but always there, that the returning of good for evil was the right way to behave, what are we to think of such a civilization which has not been able to talk about the prospect of killing everybody, or almost everybody, except in terms of calculation and prudence? (apud BURKE, 2007, p. 187-188)

Burke (2007, p. 188) destaca que Oppenheimer interrogou "o silêncio" em torno da bomba atômica que inibia o debate sobre sua existência e seu uso potencial. O físico não se contentou em rebater o que era dito sobre as armas nucleares, ele apontou para o que não era dito, o que não podia ser dito, por uma razão autárquica e restrita. Ele se opôs a todo um sistema de pensamento cujo propósito era limitar a própria atividade de pensar e, em particular, de pensar eticamente sobre o uso da força, fora dos "iron walls of calculation and prudence" (BURKE, 2007, p. 188). 
De fato, as armas nucleares são consideradas incompativeis com a moral e a ética. A discussão nuclear é acusticamente isolada do debate moral. Não é possível falar sobre a bomba atômica e sobre princípios éticos ao mesmo tempo, um discurso abafa o outro. Jervis (1989, p. 114) ressalta que os fatos básicos da era nuclear talvez sejam irreconciliáveis com nossos impulsos morais. Nessa perspectiva, Aron (1976, p. 175) nota que a dissuasão nuclear preserva uma paz imoral. 0 autor sublinha que a razão estratégica se funda em um pensamento instrumental que, por definição, não formula nenhum imperativo categórico, nenhuma proibição incondicional. Todas as especulações sobre as armas nucleares admitem, hipoteticamente, seu uso. Aron (1976, p. 174, tradução nossa) constata que: "a razão dos estrategistas nucleares é, por essência, imoral porque ela aceita e decide condicionalmente um ato perverso, o extermínio de milhões de seres humanos". Por conseguinte, a ameaça de usar uma bomba atômica já é por si só monstruosa. Contudo, para os realistas, a razão estratégica é um mal necessário. A política internacional é, fatalmente, separada da moral. Stefano Guzzini (2012, p. 31) observa que o realismo contempla o mundo como um palco de tragédia permeado por conflitos eternos e por escolhas inevitáveis. Assim, a dissuasão nuclear é recomendada como uma solução pragmática e responsável para os dilemas de uma "amarga realidade".

\subsection{Apelo da Norma: A Emergência de um Tabu Nuclear}

Nina Tannenwald (2007) desafia a concepção realista da política internacional. A autora adota um ponto de vista construtivista, realçando as normas, as identidades e as interações sociais que estruturam a esfera mundial. Ela destaca a importância de elementos culturais, políticos e históricos na discussão sobre a bomba atômica. Deste modo, Tannenwald indica que a doutrina da dissuasão não é suficiente para explicar porque as armas nucleares não foram usadas desde Hiroshima e Nagasaki. A autora argumenta que outros fatores, além da razão, inibem o uso de armas nucleares. Ela retraça a emergência de um "tabu nuclear". O tabu pesa sobre os Estados que optam por não recorrer ao arsenal nuclear, até mesmo contra rivais incapazes de revidar. A dissuasão se baseia na destruiç̧ão mútua. Se o inimigo não possui armas nucleares, não há razão para não usá-las. Mas há uma norma:

This norm is essential to explain why nuclear weapons have remained unused even when it might have been militarily advantageous to use them, and in accounting for their special status as "taboo" weapons. The effect of this taboo has been to delegitimize nuclear weapons as weapons of war, and to embed deterrence practices in a set of norms, both regulative (regulating behavior) and constitutive (defining roles and identities), that stabilize and restrain the self-help behavior of states. (TANNENWALD, 2007, p. 3)

Apesar de não existir uma proibição formal, inscrita no direito internacional, Tannenwald sublinha o vigor do estigma que cerca a bomba atômica. Gradualmente, as armas nucleares se tornam armas moralmente "inaceitáveis". Ademais, os Estados não nucleares também moldaram suas expectativas em função do tabu: sabendo que não seriam alvos de ataques nucleares, muitos deles escolheram não adquirir a bomba. Outros Estados, até mesmo sem a 
proteção do "guarda-chuva" nuclear americano, seguiram o mesmo caminho. O discurso realista é inadequado para elucidar essa escolhas.

Logo, Tannenwald examina as especificidades do tabu nuclear. Ela destaca que o tabu é um tipo peculiar de norma que é tida como absoluta e inviolável (TANNENWALD, 2007, p. 11). O tabu se firma em um sentimento de repulsa inefável. O horror, causado pela bomba, é tão visceral que ele não pode ser descrito por palavras. Deste modo, o tabu é rodeado de silêncio, ele tende a se tornar um pressuposto compartilhado, porém "não dito" (TANNENWALD, 2007, p. 52). Quando a norma está enraizada, ninguém precisa mais falar sobre ela. A norma é a cristalização de um processo argumentativo. Depois do debate sobre as armas nucleares, a convicção de que elas não devem ser usadas se impôs. O assunto não precisa mais ser discutido porque um certo consenso foi alcançado.

0 problema é que o tabu em torno do uso corre o risco de silenciar outras discussões. Por exemplo, se não haverá mais um uso futuro, por que falar do uso passado? A emergência de um tabu nuclear, de certa forma, "redimiria" Hiroshima e Nagasaki, eventos terriveis porém únicos. É como se a norma "corrigisse" essas "aberrações" que foram os primeiros bombardeios atômicos. Eles não voltarão a acontecer, os Estados Unidos "aprenderam a lição". O escritor Milan Kundera (1990, p. 14, tradução nossa) denuncia a "perversão moral inerente a um mundo fundado essencialmente na ausência do retorno". Para ele, se não há um eterno retorno, se o tempo é linear e irreversível, as atrocidades são de antemão absolvidas. A fugacidade se torna uma circunstância atenuante: o que aconteceu em Hiroshima e Nagasaki pode ser perdoado como um mal efêmero. O perdão substitui a justiça. Ademais, o tabu sobre o uso pode calar o debate sobre a possessão de armas nucleares. Por que falar sobre o desarmamento se os arsenais não são usados? Por que pressionar os Estados se eles já são tão "responsáveis"? A bomba atômica continua a existir, encoberta pelo silêncio.

Por outro lado, Tannenwald (2007, p. 11) observa que o tabu se contrapõe à atração exercida pela bomba atômica. As armas nucleares são ambivalentes, objetos de aversão e desejo. Seu poder é, ao menos tempo, inebriante e aterrador. Logo, a autora identifica os efeitos "transformativos" de uma eventual violação do tabu nuclear: se a linha entre o uso e o não uso for atravessada, nós estaríamos imediatamente em um mundo novo (TANNENWALD, 2007, p. 11). Portanto, a violação do tabu é mais grave do que a infração de uma norma habitual, que pode ser punida sem que a situação "normal" mude.

Além disso, o tabu se inscreve em relações intersubjetivas: uma coisa é "tabu" porque as pessoas acreditam que ela seja. O fato da palavra "tabu" ser usada (e Tannenwald demonstra que os responsáveis americanos a usaram em inúmeras ocasiões) revela como os usuários compreendem o mundo. As percepções dos atores constituem e são constituídas pelo termo. Nessa perspectiva, o tabu nuclear passou a integrar o discurso contemporâneo da "civilização" (TANNENWALD, 2007, p. 46). Os líderes "civilizados" podem dispor de arsenais nucleares porque eles são respeitosos do tabu. Já líderes "bárbaros" são imprevisíveis e devem ser impedidos de adquirir armas nucleares. Todavia, apesar de estabelecer uma hierarquia entre os Estados, o tabu nuclear se distingue por ter surgido a partir de uma mobilização "bottom up". A voz da sociedade civil foi decisiva para cimentar a norma. A ONU também contribuiu na formação do tabu. Ao definir a categoria "armas de destruição em massa", a organização serviu de tribuna 
para a estigmatização coletiva das armas nucleares. Finalmente, o empenho dos países do Sul foi primordial para a consolidação do tabu.

Tannenwald (2007, p. 25) derruba a separação entre a razão e a moral, discernindo o vínculo estreito entre interesse racional e moralidade na política nuclear. 0 tabu nuclear seria uma norma moral. Ele foi instaurado porque as armas nucleares violam de forma flagrante os princípios morais de discriminação e proporcionalidade no uso da força (TANNENWALD, 2007, p. 58). Não obstante, a autora ressalva que a emergência do tabu não deve ser lida apenas como uma história de "progresso moral" mas como um processo de deslegitimação de uma determinada forma de violência - e aceitação de outras. Ao reconhecer a singularidade das armas nucleares, o tabu "permite" o uso de armas convencionais. Em 1948, o Presidente Truman, assombrado por Hiroshima e Nagasaki, insistiu que a bomba atômica não podia ser comparada às demais armas militares:

I don't think we ought to use this thing [the atomic bomb] unless we absolutely have to. It is a terrible thing to order the use of something... that is so terribly destructive, destructive beyond anything we have ever had. You have got to understand that this isn't a military weapon. .. It is used to wipe out women and children and unarmed people, and not for military uses. So we have got to treat this differently from rifles and cannon and ordinary things like that. (apud TANNENWALD, 2007, p. 111)

A bomba atômica se diferencia dos "rifles, canhões e outras coisas ordinárias" e se instaura como uma arma excepcional, uma arma de último recurso, que não deve ser usada se ela não for absolutamente "necessária". Em outras palavras, a bomba atômica é, por excelência, a arma da exceção. Ela é a arma que só pode ser usada como exceção, durante a exceção. Quando a exceção é declarada, as normas, inclusive o tabu nuclear, se calam. Carl Schmitt (2005, p. 13) anuncia: não existem normas aplicáveis ao caos.

\section{Ordem Soberana e Apocalipse Nuclear}

\subsection{Exceção e Desigualdade: O Clube dos Soberanos Atômicos}

O tabu nuclear fez com que o uso da bomba atômica se tornasse mais "improvável." Tannenwald demonstrou que, em diversas situações onde armas nucleares poderiam ter sido usadas, como na Coreia, no Vietnã ou no Golfo, os Estados Unidos se conformaram com a norma e não recorreram ao arsenal à sua disposição. Alguns líderes militares defenderam - com fervor - o uso de armas nucleares, porém, o tabu prevaleceu. Tannenwald (2007, p. 2) reconhece que a "sorte" desempenhou um papel na decisão de não usar as armas nucleares. As normas não são onipotentes e, por sorte, o estado de exceção não se instalou. De fato, Schimtt (2005, p. 12) indica que a norma é destruída na exceção. O Estado tem o poder de suspender a lei com base no seu direito de autopreservação. Se a vida da comunidade política estivesse em jogo, a ordem legal passaria a se fundar exclusivamente na decisão soberana. Se os Estados Unidos fossem confrontados com uma emergência extrema e a exceção fosse decidida, o tabu se desmancharia e a bomba atômica poderia, sim, ser usada. 
De acordo com Tannenwald (2007, p. 367), o tabu é uma proibição absoluta que não é necessariamente interrompida por sua violação. A regra do não uso resistiria à exceção do uso. Não obstante, a continuidade do tabu nuclear dependeria das circunstâncias de sua violação. Se as armas nucleares fossem usadas por atores não estatais ou por um Estado dito "periférico", a comunidade internacional poderia coordenar medidas repressivas. 0 desvio da norma poderia ser punido. Mas se os Estados Unidos resolvessem empregar armas nucleares, seria mais difícil penalizar a transgressão e assegurar a validade do tabu. Os Estados Unidos efetivamente já desrespeitaram outras normas internacionais antes e nem por isso elas desapareceram. Ao interpretar de forma abusiva a noção de "legítima defesa" e declarar uma guerra preventiva contra o Iraque em 2003, o Estado americano fez uso ilícito da força. A norma sobre o uso da força continua a existir, inscrita na Carta da ONU, porém ela foi enfraquecida. Se o mesmo acontecesse com o tabu nuclear, as consequências seriam ainda mais alarmantes. 0 tabu sobreviveria mas o mundo sofreria transformações severas e irremediáveis.

Schmitt (2005, p. 5) enfatiza que o soberano é aquele que decide a exceção. O soberano garante as normas; entretanto, se ele julgar necessário, as normas são diluídas na exceção. Além de definir a necessidade, o soberano também distingue o amigo do inimigo. 0 inimigo ameaça a existência da comunidade - se essa ameaça for considerada máxima, a destruição total do inimigo pode ser preconizada. O soberano decide se existe uma emergência extrema e o que deve ser feito para eliminá-la (SCHMITT, 2005, p. 7). As armas nucleares oferecem um meio de aniquilação ímpar que pode ser cogitado. Por conseguinte, enquanto existam armas nucleares e Estados soberanos, Hiroshima e Nagasaki poderão voltar a acontecer. 0 discurso do Presidente Kennedy do dia 22 de outubro de 1962, em plena crise do mísseis de Cuba, ilustra essa possibilidade: "We will not prematurely or unnecessarily risk the costs of worldwide nuclear war in which even the fruits of victory would be ashes in our mouth - but neither will we shrink from that risk at any time it must be faced" (apud BURKE, 2007, p. 269). Apesar de todas as salvaguardas, o soberano pode ser levado a assumir o risco de explodir o mundo.

Por outro lado, as armas nucleares fazem com que alguns soberanos sejam "mais soberanos" do que outros. Tannenwald (2007, p. 360) explica que o regime de não proliferação impõe uma hierarquia entre os Estados "responsáveis" que podem possuir armas nucleares e os Estados que não são "confiáveis" o suficiente para manter o tabu. O Tratado de Não Proliferação Nuclear (1968) é marcado por seu caráter discriminatório, separando os seus signatários em duas categorias: os detentores reconhecidos de armas nucleares e o resto. Segundo a autora, as identidades criadas pelo regime desafiam a igualdade soberana, sacrificada em nome da segurança coletiva. Deste modo, as armas nucleares se tornam os alicerces de uma ordem desigual. Todos os membros permanentes do Conselho de Segurança possuem a bomba atômica. É como se a bomba fosse a chave de entrada para um círculo de potências superiores, "a select priesthood with regard to the taboo objects" (TANNENWALD, 2007, p. 12).

A desigualdade é acentuada pela produção de um discurso da "civilização", mencionado anteriormente. Se um Estado não faz parte do "clube" dos soberanos atômicos, mas insiste em desenvolver armas nucleares, ele é qualificado de "bárbaro". Segundo Cimbala (2005, p. 95), hoje em dia, as armas de destruição em massa são julgadas "obsoletas" e relegadas a um passado primitivo. O Estado que ainda deseje a bomba é "atrasado" e, portanto, 
indigno dessa tecnologia. Logicamente, ele deve ser disciplinado. E, sendo um "bárbaro", ele não precisa ser tratado de acordo com o direito, válido apenas entre nações civilizadas (TANNENWALD, 2007, p. 46). Assim, é possivel declarar uma guerra preventiva, desdenhar as normas humanitárias ou, até mesmo, usar armas nucleares. Tannenwald (2007, p. 385) salienta o risco dos Estados Unidos legitimarem o uso de armas nucleares (sobretudo, de "mini-nukes"2) para fazer com que os "bárbaros" cumpram o regime de não proliferação.

O discurso da civilização pode ser criticado por sua injustiça e violência. Tzvetan Todorov (2010, p. 16) sublinha que os bárbaros são aqueles que negam a humanidade plena dos outros. Foram os Estados Unidos, esse "exemplo" de civilização, que lançaram duas bombas atômicas sobre Hiroshima e Nagasaki. A humanidade dos japoneses foi negada. Argumentos racistas (TANNENWALD, 2007, p. 90) justificaram a decisão de testar as novas armas sobre uma população asiática. Aos olhos americanos, os japoneses eram "menos que humanos" e, portanto, poderiam servir de cobaias para as armas nucleares. Quem é o bárbaro então? Noam Chomsky e Andre VItchek (2013) publicaram um livro chamado On Western Terrorism: From Hiroshima to Drone Warfare. 0 título coloca Hiroshima como o início de uma longa e vergonhosa história de "terrorismo ocidental".

As falácias do discurso da civilização e o desprezo pela igualdade fundamental entre seres humanos são denunciados por pensadores pós-coloniais. Himadeep Muppidi (2012, p. 20) se apropria da dor de Hiroshima e Nagasaki como um símbolo da dor do Outro:

Mine is the body you cremated twice, thoughfully: once in Hiroshima and again in Nagasaki. Come anniversary time in August, you are suddenly silent, uncertain about whether to celebrate your technology or atone for the mass vaporizations? But, all year around, you are outraged or terrified that darker rogues might access your destructive wisdom.

As armas nucleares, mesmo se elas nunca mais forem usadas, possuem efeitos produtivos nefastos. Elas elevam alguns soberanos - e alguns povos - acima de outros, conferindo-Ihes um poder apocalíptico.

\subsection{Ciência, Fé e Soberania: O Imaginário Político do Apocalipse Nuclear}

Além de agravar a desigualdade entre Estados soberanos, a bomba atômica dá origem a um imaginário peculiar: o imaginário do apocalipse nuclear. Podemos estudar as implicações simbólicas das armas nucleares a partir da etimologia da palavra "tabu", analisada por Sigmund Freud (2001). De origem polinésia, "tabu” é um termo ambíguo. Ele designa algo que é, ao mesmo tempo, sagrado e profano, venerável e perigoso, intocável e maligno, divino e demoníaco. A fonte do tabu é atribuída a um "poder mágico peculiar" inerente a pessoas ou a espíritos, e que pode ser transmitido através de objetos inanimados (FREUD, 2001, p. 24). As armas nucleares são artefatos tabu que conferem um poder sobrenatural aos seus possessores: elas têm a capacidade de destruir o mundo. A dimensão "divina" da bomba

2 Os chamados "mini-nukes" são armas nucleares mais pequenas e precisas. Elas desafiam o tabu nuclear porque elas borram a linha entre armas convencionais e armas nucleares, fazendo com que o uso de armas nucleares seja reconsiderado (TANNENWALD, 2007, p. 383). 
atômica é palpável nas metáforas usadas pela literatura nuclear. Uma imagem recorrente é a do Armagedom³: a guerra nuclear seria a última batalha antes do fim dos tempos. As doenças causadas pela radiação são chamadas de "peste nuclear" (OE, 2012, p. 205), uma praga com conotações apocalípticas. Por sua vez, os cientistas do Projeto Manhattan são representados como "Prometeus modernos" que escalaram o Monte Olimpo e roubaram "os raios de Zeus."4 Oppenheimer, ao narrar a primeira detonação nuclear, cujo codinome era "Trinity", recorre a referências metafísicas:

We knew the world would not be the same. A few people laughed, a few people cried, most people were silent. I remembered the line from the Hindu scripture, the Bhagavad-Gita. Vishnu is trying to persuade the Prince that he should do his duty and to impress him takes on his multi-armed form and says, "Now, I am become Death, the destroyer of worlds." I suppose we all thought that one way or another. (apud CAVALIERI, 1982, p. 73)

A violência nuclear é inserida em um imaginário mítico, a destruição toma proporções vertiginosas e sobre-humanas.

Por outro lado, a explosão da bomba, com sua célebre nuvem em forma de cogumelo, produz um espetáculo visual que entorpece os sentidos e que, como o sublime, coíbe a capacidade de pensar (BUTLER, 2004, p. 148). Judith Butler critica a dimensão estética da doutrina militar americana de "shock and awe", uma doutrina cujas origens podem ser encontradas em Hiroshima. A lendária imagem da bomba aterroriza, cativa e, finalmente, anestesia o imaginário coletivo. Ao admirar essa nuvem colossal, esquecemos que havia pessoas sendo dizimadas naquele exato momento em que a fotografia foi tirada. Nessa perspectiva, Walter Benjamin (2008, p. 38) alerta que a humanidade se tornou um espetáculo para ela mesma: "its alienation from itself has reached a point where it now allows its own destruction to be savoured as an aesthetic pleasure of the first order". De fato, os próprios líderes militares fazem a guerra como se fosse um show. Hap Arnorld, da Força Aérea americana, intensificou os bombardeios quando o conflito estava prestes a acabar porque ele queria "as big a finale as possible" (apud TANNENWALD, 2007, p. 80).

De acordo com Bertrand Russell (1990, p. 7), a ciência e a religião são duas faces da vida social que estiveram, durante séculos, em oposição. O espetacular apocalipse nuclear transcende essa dicotomia de forma tenebrosa: a destruição divina é forjada pela ciência, que vira a origem de um temor religioso. O "fim dos tempos" se tornou possível em um laboratório no Novo México. Esse poder, comparável ao de um Deus, é entregue nas mãos do soberano. Os cientistas se tornam cúmplices do Estado que financia suas pesquisas em troca de novos instrumentos de violência. Zygmunt Bauman (1998, p. 133) denuncia a conivência da ciência moderna:

A emancipação da razão face às emoções, da racionalidade ante as pressões normativas, da eficiência em relação à ética era o lema da ciência desde os primórdios. Uma vez concretizado, porém, esse lema fez da ciência e das formidáveis aplicações que ela gerava dóceis instrumentos nas mãos de um poder inescrupuloso.

3 Como no título do livro de Robert Jervis (1989): The Meaning of the Nuclear Revolution: Statecraft and the Prospect of Armageddon.

4 "Modern Prometheans have raided Mount Olympus again and have brought back for man the very thunderbolts of Zeus." - Scientific Monthly, September 1945. (apud BIRD; SHERWIN, 2006) 
Assim, as armas nucleares e seu teor simbólico são recuperados pela "fé soberana". Paul W. Kahn (2008) contesta a concepção liberal do Estado moderno. Para o autor, o Estado não é apenas um provedor de segurança. O Estado é um Deus mortal, uma experiência sensivel do sagrado, que reivindica o sacrifício de seus cidadãos, e o sacrifício de outros em nome de seus cidadãos. A bomba atômica é, então, uma forma de violência sagrada: Hiroshima e Nagasaki foram sacrificadas no altar do soberano americano, para "salvar" vidas americanas. Ao mesmo tempo, essa demonstração de força invalidou o sacrifício dos japoneses. As vítimas do massacre nuclear foram degradadas, vaporizadas, queimadas, envenenadas e, portanto, condenadas a uma morte sem sentido. O objetivo era reduzir o corpo do inimigo a nada além de um campo para a exibição do próprio poder soberano (KAHN, 2008, p. 164). Deste modo, o soberano japonês foi derrotado, não só materialmente mas "simbolicamente".

Tanto a religião, quanto a ciência, e a soberania, requerem o silêncio. A religião exige o silêncio da prece, da prostração diante do mistério da fé. A ciência, com sua linguagem especializada e técnica, exige o silêncio do leigo. A soberania, ao exercer o terror (KAHN, 2008, p. 17), exige o silêncio de todos ao seu redor. Nesse contexto, como podemos restaurar a fala e a política? Kahn sugere uma forma: escutando o testemunho do veterano. 0 veterano, ou o sobrevivente em geral, diz o que não pode ser dito, ele diz que "there was no experience of a sacred sovereign but only of murder and death" (KAHN, 2008, p. 160). Ele fala contra o soberano, contra a guerra, contra a violência sagrada e, por isso, ele é silenciado: a nação não pode tolerar essa "lição do universal" (KAHN, 2008, p. 161). Para resgatar a fala, devemos tentar escutar essa lição e, portanto, transpor o silêncio.

\section{Som do Silêncio: Os Hibakusha e A Violência Lenta}

\subsection{Escutar os Hibakusha: Política e Dignidade Humana}

Durante anos, os sobreviventes de Hiroshima e Nagasaki - os "hibakusha" 5 - foram silenciados e a "lição do universal" não pôde ser ouvida. O Código da Imprensa, instaurado no dia 19 de setembro de 1945 por militares americanos, proibia toda difusão de informações ou comentários relativos aos bombardeios atômicos, seja na imprensa, no cinema ou na rádio (OE, 2012, p. 97). Em regra geral, era proibido falar em público sobre o assunto. Os responsáveis americanos censuravam os dados sobre os efeitos da radiação nas vítimas e sobre as mortes que continuavam a ocorrer. Os Estados Unidos temiam uma possível analogia entre a radiação e o gás venenoso, arma banida pela comunidade internacional. Para evitar que as armas nucleares fossem deslegitimadas, o Departamento de Guerra dissimulava as provas e insulava os hibakusha (TANNENWALD, 2007, p. 96).

O Japão voltou a ser independente em 1952 e o Código da Imprensa foi revogado (OE, 2012, p. 97). Entretanto, quando os hibakusha puderam falar, muitos japoneses não quiseram

5 "Hibakusha" é uma palavra japonesa que significa "pessoas afetadas pela explosão". Ela designa as vítimas dos bombardeios atômicos (OE, 2012, p. 23). 
ouvir. Takeshi Ishida (1989) nota que os hibakusha eram discriminados pela sociedade nipônica. Por terem sido expostos à bomba, estes indivíduos se tornaram "tabu". Alguns deles deixaram Hiroshima ou Nagasaki, ocultando suas identidades de sobreviventes. Eles tentaram deixar o passado para trás, mas ele voltava, sob a forma de doenças (OE, 2012, p. 163). Outros hibakusha se refugiaram na solidão. Não se casaram, não formaram famílias, por medo de transmitir a "peste nuclear" para as futuras gerações (OE, 2012, p. 81). Muitas mulheres de Hiroshima, desfiguradas por queloides, passaram o resto da vida trancadas em casa, confinadas pela vergonha (OE, 2012, p. 154). Outras vítimas da bomba, confrontadas com os efeitos degradantes da radiação, enlouqueceram ou se suicidaram (OE, 2012, p. 89). Kahn (2008, p. 165) observa que o suicídio é um protesto contra a degradação: "Suicide is the act of taking possession of one's death". Com pesar, Oe (2012, p. 124) constata que os japoneses têm ao menos a sorte de viver em um país não cristão, onde o suicídio não é pecado. Alguns hibakusha preferiram o suicídio à morosa agonia causada pela bomba. Ao acabar com a própria vida, o suicida afirma seu poder de escolha, sua liberdade. Todavia, essa liberdade é desesperada e efêmera: ela se realiza e se extingue na morte.

O silêncio dos hibakusha apresenta um desafio político. Ausentes do espaço público, os sobreviventes permanecem invisíveis. Segundo Arendt (1990, p. 98), na política "being and appearance are indeed one and the same". Ou seja, os hibakusha não existiriam politicamente porque eles não "aparecem" em público, porque eles estão reclusos na esfera privada. O reconhecimento surge como uma dimensão fundamental da subjetividade política. Jacques Rancière (2001, Thesis 8) levanta essa questão:

If there is someone you do not wish to recognize as a political being, you begin by not seeing them as the bearers of politicalness, by not understanding what they say, by not hearing that it is an utterance coming out of their mouths [...] In order to refuse the title of political subjects to a category - workers, women, etc. - it has traditionally been sufficient to assert that they belong to a "domestic" space, to a space separated from public life; one from which only groans or cries expressing suffering, hunger, or anger could emerge, but not actual speeches demonstrating a shared aesthesis.

Assim, a própria esfera pública é circunscrita pelo silêncio, pelo limite entre quem pode e quem não pode ser ouvido. Segundo Butler (2004, p. xvii), o espaço público é constituído por o que não pode ser dito e o que não pode ser mostrado. As histórias dos hibakusha se encontram atrás dessas fronteiras. Muitas vítimas fazem parte do espaço "doméstico": são mulheres, crianças, idosos e doentes cujo sofrimento não é interpretado como um fenômeno político. Porém, esse sofrimento foi causado por Estados, tanto o americano quanto o japonês6, ele é intrinsecamente público e precisa ser ouvido em público.

Oe conta a história de um rapaz que, depois de dores lancinantes, morreu de leucemia. Ele tinha quatro anos quando foi atingido pela bomba: "Ele não era responsável pela guerra, aliás, ele nem sequer compreendia o porquê desse ataque nuclear tão absurdo, tão inesperado.

6 Com níveis de responsabilidade distintos, é claro. Os Estados Unidos lançaram a bomba, o Japão insistiu em continuar a guerra em detrimento de sua população. 
No entanto, foi essa criança que, vinte anos depois, assumiu no próprio corpo a responsabilidade do Estado" (OE, 2012, p. 224, tradução nossa). Uma semana após a morte, a noiva do jovem voltou ao hospital e agradeceu, serenamente, a todos os médicos que cuidaram dele. À noite, ela se suicidou. A comunidade política é responsável por essas duas mortes, e por tantas outras, ela é responsável por esse sofrimento. Nós somos responsáveis. Ashis Nandy (2009, p. xix) ressalta que todo sofrimento feito pelo homem é um e todos são responsáveis. Logo, devemos responder pelo o aconteceu em Hiroshima e Nagasaki. E, para isso, temos que saber o que aconteceu, e como aconteceu - temos que escutar os hibakusha.

Como romper o silêncio dos hibakusha? A questão é delicada. Alguns sobreviventes invocam o direito de permanecer calados (OE, 2012, p. 23). Eles se recusam a serem objetos de pena, a terem suas falas recuperadas por porta-vozes de movimentos políticos e lutas antinucleares. Eles não querem ser definidos como meras vítimas. Eles não querem que suas identidades e trajetórias complexas sejam condicionadas por uma manhã de agosto. De certa forma, eles compartilham a visão de Arendt (1990, p. 88). A autora denuncia a piedade como uma expropriação perversa do infortúnio do Outro.

Outros hibakusha desejam falar e são "escolhidos" para falar em ambientes controlados, como em cerimônias oficiais ou em conferências internacionais sobre o desarmamento nuclear. Apesar dessa fala possuir um valor inegável, ela é bastante consensual e não desestabiliza o discurso soberano. Para Rancière (2001, Thesis 8), a política genuína aflora da dissensão. Nessa perspectiva, uma fala plenamente política seria aquela que não se conformaria com as regras do jogo. A fala política mostraria que, muito além do mundo dos Estados soberanos, do mundo que justifica a violência como necessária, existe um mundo humano onde a dignidade de cada pessoa importa. É nessa fala que nós podemos encontrar "a lição do universal” (KAHN, 2008, p. 161).

A literatura da bomba atômica, um campo da literatura japonesa, oferece exemplos dessa lição: ela retraça as histórias e as vidas cotidianas dos sobreviventes. Essas histórias nos colocam no lugar do hibakusha, nos conectam ao seus "lifeworlds"7 e, assim, nos fazem compreender as formas que a violência e o poder tomaram após Hiroshima e Nagasaki. Butler (2004, p. 8) sublinha o valor das narrativas que decentralizam o "Eu", dando espaço ao Outro:

The ability to narrate ourselves not from the first person alone, but from, say, the position of the third, or to receive an account delivered in the second, can actually work to expand our understanding of the forms that global power has taken.

Apesar de não ser um sobrevivente dos bombardeios, Oe nos traz inúmeras histórias e testemunhos de hibakusha. Uma delas é de um avô que, depois de ter a família exterminada, criou sozinho o neto (OE, 2012, p. 126). O rapaz entrou na prestigiosa Universidade de Tóquio mas, devido a dificuldades financeiras, teve que interromper seus estudos. Ele não conseguiu encontrar trabalho por causa de seus sintomas: ele estava sempre exausto, sua visão diminuía e seus rins começaram a falhar. Quando ele voltou a Hiroshima, ele foi internado e morreu após uma longa agonia. 0 avô se murou no silêncio, passou dias e dias sentado diante do altar de

7 "Lifeworld" é um conceito oriundo da fenomenologia, ele designa o mundo tal como ele é vivido e experienciado pelo sujeito. 
seus antepassados. Então, de repente, ele começou a falar, a falar sem parar, com seu neto falecido. 0 avô foi entrevistado e explicou: "Ryu-chan, ele morreu antes de mim, por isso, agora ele me diz 'Vamos, vovô, venha, sobretudo não erre o caminho!' Agora, para que serve remoer essa história de bombardeio atômico? Se o senhor Tojo ${ }^{9}$ tivesse desaparecido um pouco antes, Ryu-chan não precisaria ter morrido. Alias, agora que ele morreu, é o que ele me diz também" (OE, 2012, p. 128, tradução nossa). A fala do avô desmente o discurso soberano, sua insanidade expõe a loucura da guerra. A fala do avô abre a "caixa-preta" do Estado: o Japão não é uma entidade divina, mas um aparato mortífero manipulado por indivíduos mesquinhos como o "senhor Tojo". A fala do avô revela que não existe violência sagrada mas apenas violência absurda e cruel. Ela revela que o soberano não confere sentido algum. A única coisa que resta, depois do "sacrifício", é uma triste e insondável ausência, é um silêncio.

\subsection{Ecos Radioativos: A Violência Lenta Após Hiroshima e Nagasaki}

A violência radioativa, sofrida pelos hibakusha, nos obriga a repensar os limites temporais da violência física causada pela guerra. A radiação continuou a provocar dor e morte décadas depois da bomba atômica ter sido lançada. Temos tendência a pensar a violência "psicológica" como um fenômeno longo: os traumas emocionais da guerra duram anos. Algumas pessoas nunca se recuperam "mentalmente" dessa experiência. Mas o corpo, sim - achamos que o corpo pode ser curado, que, apesar das sequelas e cicatrizes, a violência sobre o corpo termina quando a paz retorna. Hiroshima e Nagasaki provam que não é bem assim. Para os sobreviventes, apesar da capitulação japonesa, a guerra estava apenas começando (OE, 2012, p. 182-183). A bomba atômica continua presente nos corpos dos hibakusha e de seus descendentes. Uma violência lenta se abate sobre seus organismos. Segundo Oe (2012, p. 270), a devastação insidiosa, que ocorre nas células e nos genes, seria a face mais hedionda do "apocalipse nuclear".

A violência lenta se alastra nas sombras da política. Rob Nixon (2011, p. 2) emprega o conceito de "violência lenta" para designar uma forma de violência que ocorre gradualmente e fora de vista; uma violência de destruição atrasada que está dispersa no tempo e no espaço; uma violência que não é tipicamente vista como violência. 0 autor ilumina o vínculo entre danos ambientais e violência. Por exemplo, as Ilhas Marshall foram sujeitas, entre 1948 e 1958, a sessenta e seis testes nucleares americanos - o maior deles equivaleu, em força, a mil bombas de Hiroshima (NIXON, 2011, p. 7). Contaminado pela radioatividade, o país foi vítima do que Nixon (2011, p. 7) chama de "colonialismo nuclear". Décadas depois dos testes, nos anos 1980, ainda nasciam bebês "medusa", crianças sem olhos, nem cabeça, nem membros, que viviam apenas por algumas horas (NIXON, 2011, p. 7). Essa violência, ocasionada por armas nucleares, é ignorada pelo tabu nuclear. Os Estados se felicitam de não terem mais usado a bomba atômica em situações de conflito. Porém, os efeitos atrozes dos testes, que ocorreram na normalidade,

8 Em japonês, "-chan" é um sufixo carinhoso. Em português, Ryu-chan seria equivalente a "Ryuzinho".

9 Hideki Tojo (1884-1948) foi um general e homem de Estado. Nomeado Primeiro-ministro em outubro de 1941, ele é considerado como o responsável pela eclosão da guerra do Pacífico. Ele foi condenado à morte durante o processo de Tóquio, e executado no dia 23 de setembro de 1948 (OE, 2012, p. 128). 
são desconsiderados. De fato, ao contrário do que Tannenwald (2007, p. 59) afirma, o limite ente o uso e o não uso é poroso.

Nessa perspectiva, podemos analisar os níveis alarmantes de radiação no Iraque. Chomsky (com VLTCHEK, 2013, p. 44) observa que os níveis de radiação na cidade de Faluja são altíssimos, praticamente os mesmos de Hiroshima, e que as armas ali utilizadas causaram danos severos ao ambiente. VItchek (com CHOMSKY, 2013, p. 44) retifica que não é apenas em Faluja, mas em todo o Iraque há lugares contaminados por graus de radioatividade que podem ser fatais. A Guerra do Golfo, edificada como um exemplo de consolidação do tabu nuclear, foi o primeiro conflito em que munições de urânio empobrecido foram usadas em larga escala (NIXON, 2011, p. 200). Apesar do discurso que louva a "precisão" das armas atuais, uma ameaça difusa e indiscriminada tomou posse do campo de batalha. Segundo Nixon (2011, p. 201), "not since Hiroshima and Nagasaki have humans unleashed a military substance so tenaciously hostile to life itself".

O uso de uma substância radioativa como arma de guerra é um legado indireto de Hiroshima e Nagasaki: o urânio empobrecido é um subproduto da fabricação de armas nucleares. Nixon (2011, p. 212) explica como ele foi integrado aos armamentos convencionais. Após mais de meio século de programa nuclear, o Departamento de Defesa americano se viu com um grande e inconveniente estoque de lixo radioativo. A forma encontrada para "reciclar" esse resíduos foi oferecê-los, de graça, para a indústria armamentista que desenvolveu e comercializou as munições de urânio empobrecido. O resultado é uma "sedutora alquimia": "weapons manufacturers magically cut their production costs while the Defense Department magically rids itself of a five-alarm waste product that no American wants buried in their backyard" (NIXON, 2011, p. 212). Os detritos tóxicos são transformados em artefatos ainda mais perigosos, destinados a assolar lugares distantes.

Ademais, Nixon salienta que o urânio empobrecido permanece no ambiente por bilhões de anos: é uma violência muito, muito duradoura. Desde 1991, ele foi usado no Afeganistão, na Bósnia, no Kosovo, no Kuwait, na Sérvia, na Somália, na Chechênia e, novamente, no Iraque (NIXON, 2011, p. 211.) Quantas "mortes lentas" ainda estão para acontecer? As mortes lentas são sub-representadas no planejamento estratégico, e na memória humana (NIXON, 2011, p. 3). É mais difícil contá-las e relacioná-las com as tecnologias bélicas:

Spikes in renal collapse; infertility; leukemia; testicular, brain, and breast cancers; and clusters of infant malformations are harder to link to war's technologies than a bullet through the head. The military statistician can simply count corpses within a given place and time, subdivide those columns into combatants and civilians, then draw a line beneath his sums. (NIXON, 2011, p. 211)

As estatísticas militares ignoram, e às vezes ocultam, a relação entre enfermidades e um tipo específico de armamento (NIXON, 2011, p. 214). O vínculo entre a morbidez e a guerra é omitido. Por essa razão, Tannenwald (2007, p. 80) insiste que a bomba atômica causou "menos destruição" do que as bombas incendiárias. A autora só leva em consideração o número de mortes imediatas e ostensivas, subestimando a destruição que continuou a ocorrer nos corpos das vítimas, décadas após o fim da guerra. Esse viés informa o pensamento dos líderes militares, 
ilustrado pela declaração do general Curtis LeMay: "We scorched and boiled and baked to death more people in Tokyo on that night of March 9-10 than went up in vapor at Hiroshima and Nagasaki combined" (apud TANNENWALD, 2007, p. 79-80).

Por ser "invisível", a violência lenta desafia a política, baseada nas aparências. A violência lenta não captura a atenção do público, acostumado com a violência "espetacular". De acordo com Nixon (2011, p. 3), existe uma grave questão representacional: como transformar os "desastres lentos" em narrativas e imagens tangiveis? Além disso, a dispersão temporal dificulta a definição da violência e de seus responsáveis. Quando a guerra termina, um novo tempo começa. O que foi feito no passado é julgado e, logo, ultrapassado. A violência lenta corrói esses indicadores temporais e invalida o julgamento. Ela é a prova inquietante de que o passado não passou. O crime não pode ser julgado, punido e esquecido porque ele ainda não acabou. Nixon (2011, p. 231) ressalta: "People may outlast a given conflict, but if untold thousands die deferred war deaths, what kind of justice is it to call them survivors?" 0 autor denuncia a conversão do planeta em uma arma biológica que ameaça a própria biologia (NIXON, 2011, p. 232). Sem deixar sobreviventes, tal arma mergulharia o mundo em um silêncio total e irreparável.

\section{Conclusão: Hiroshima e Nagasaki no presente}

Ao longo do artigo, analisamos as consequências políticas e éticas dos bombardeios atômicos de Hiroshima e Nagasaki. Começamos avaliando o que tinha sido dito sobre as armas nucleares. O discurso mais difundido, logo depois dos acontecimentos, foi o da dissuasão. A razão estratégica se impôs durante a Guerra Fria: as grandes potências procuraram controlar o potencial destrutivo das novas armas e pregaram o equilíbrio do terror. Esse discurso era embasado por pressupostos realistas, que implicam a separação da política e da moral. Tannenwald oferece um argumento dissonante. A autora mostra como a moral e os interesses políticos se interpenetram. Ela salienta que a emergência de um "tabu nuclear" é um fator decisivo para compreender o não uso de armas nucleares.

Em seguida, examinamos os limites da norma proposta por Tannenwald. Primeiro, analisamos o elo entre exceção e soberania. As normas, até mesmo o tabu nuclear, se diluem na exceção, decidida pelo soberano. Por isso, enquanto existam soberanos e arsenais nucleares, Hiroshima e Nagasaki poderão voltar a acontecer. Além disso, as armas nucleares produzem uma ordem desigual porque elas conferem um poder superior a alguns Estados, membros de um círculo seleto. Ademais, exploramos o imaginário político do "apocalipse nuclear". Vimos como a religião, a ciência e a soberania se fundem em um "espetáculo" de destruição. Concluímos que a bomba atômica é um artefato tabu que fortalece a fé no soberano. Essa fé transcende razões, normas e estratégias e, portanto, escapa aos discursos dominantes sobre as armas nucleares.

Enfim, tentamos resgatar a fala e a política dos escombros de Hiroshima e Nagasaki. Observamos os desafios que entravam os testemunhos dos hibakusha. Apesar dos obstáculos, vislumbramos algumas histórias que contribuíram para a formação de uma abordagem crítica. As falas dos sobreviventes desestabilizam o discurso soberano porque elas estão impregnadas 
por uma "lição do universal". Essa lição ainda ecoa. A violência "lenta" que se abateu sobre os hibakusha após a Segunda Guerra Mundial continua a atacar em lugares devastados por testes nucleares e armas tóxicas. A violência lenta mata na normalidade, ela se alastra nas sombras da política e se acomoda no silêncio indiferente.

A questão da violência lenta nos revela uma forma de trazer Hiroshima e Nagasaki para o presente. Não basta comemorar o aniversário dos bombardeios atômicos em uma cerimônia solene e oficial, fadada a ser esquecida no dia seguinte. É crucial questioná-los, repensá-los, encontrar conexões entre o passado e o presente, o aqui e o lá. É crucial ter a coragem de pensar sobre o que significa ser um sobrevivente de Hiroshima e Nagasaki, e o que pode ser feito a partir disso. Kenzaburo Oe (2012, p. 144, nossa tradução) declara: "Hiroshima é como uma ferida aberta, a mais profunda que a humanidade já sofreu. Lá afloram duas possibilidades: a esperança de uma cura do humano ou o risco de sua decomposição". Hiroshima e Nagasaki podem se tornar faróis para a restauração da dignidade humana. Os eventos passados podem se tornar recursos para criticar o presente. É possível usar a força simbólica dessas cidades únicas para iluminar a violência sofrida em lugares menos visíveis. Não podemos continuar atomizados e desatentos - devemos ir além do silêncio atômico.

\section{Referências Bibliográficas}

ARISTÓTELES. 1988. Política. Madrid: Editorial Gredos.

ARENDT, Hannah. 1990. On Revolution. London: Penguin.

ARON, Raymond. 1976. Penser la Guerre, Clausewitz, Tome II: L'Âge Planétaire. Paris: Gallimard.

BAUMAN, Zygmunt. 1998. Modernidade e Holocausto. Rio de Janeiro: Zahar.

BENJAMIN, Walter. 2008. The Work of Art in the Age of Mechanical Reproduction. London: Penguin.

BIRD, Kai; SHERWIN, Martin J. 2006. American Prometheus: The Triumph and Tragedy of J. Robert Oppenheimer. New York: Vintage.

BURCHETT, George; SHIMMIN, Nick. (Ed.). 2007. Rebel Journalism: The Writings of Wilfred Burchett. Cambridge: Cambridge University Press.

BURKE, Anthony. 2007. Beyond Security, Ethics and Violence: War Against the Other. New York: Routledge.

BUTLER, Judith. 2004. Precarious Life: The Powers of Mourning and Violence. London: Verso.

CAVALIERI, Liebe F. 1982. Twin perils: nuclear science and genetic engineering. Bulletin of the Atomic Scientists, v. 38, n. 10, p. 72-75.

CHOMSKY, Noam; VLTCHEK, Andre. 2013. On Western Terrorism: From Hiroshima to Drone Warfare. London: Pluto Press.

CIMBALA, Stephen J. 2005. Nuclear Weapons and Strategy: U.S. Nuclear Policy For the Twenty-First Century. New York: Routledge. 
DURAS, Marguerite. 1961. Hiroshima Mon Amour. New York: Grove Press.

FREUD, Sigmund. 2001. Totem and Taboo: Some Points of Agreement between the Mental Lives of Savages and Neurotics. London: Routledge Classics.

GUZZINI, Stefano. 2013. Realism in International Relations and International Political Economy: The continuing story of a death foretold. London: Routledge.

IRIYE, Akira. 1981. Power and Culture: The Japanese-American War 1941-1945. Cambridge: Harvard University Press.

ISHIDA, Takeshi. 1989. Japanese Political Culture: Change and Continuity. New Brunswick: Transaction Publishers, 1989.

JERVIS, Robert. 1989. The Meaning of the Nuclear Revolution: Statecraft and the Prospect of Armageddon. Ithaca: Cornell University Press.

KAHN, Paul W. 2008. Sacred Violence: Torture, Terror, and Sovereignty. Ann Arbor: The University of Michigan Press.

KUNDERA, Milan. 1990. L'Insoutenable Légèreté de l'Être. Paris: Gallimard.

MUPPIDI, Himadeep. 2012. Colonial Signs of International Relations. London: Hurst.

NANDY, Ashis. 2009. The Intimate Enemy: Loss and Recovery of Self under Colonialism. New Delhi: Oxford India Paperbacks.

NIXON, Rob. 2011. Slow Violence and the Environmentalism of the Poor. Cambridge: Harvard University Press.

OE, Kenzaburo. 2012. Notes de Hiroshima. Paris: Gallimard, Folio.

RANCIĖRE, Jacques. 2011. Ten Theses on Politics. Theory and Event. v. 5, n. 03. Disponivel em: <http://www.egs.edu/faculty/jacques-ranciere/articles/ten-thesis-on-politics>. Acesso 27 jan. 2015.

RUSSEL, Bertrand. 1990. Science et Religion. Paris: Gallimard, Folio Essais.

SAGAN, Scott D.; WALTZ, Kenneth N. 1995. The Spread of Nuclear Weapons: A Debate. New York: W. W. Norton \& Company.

SCHMITT, Carl. 2005 Political theology: four chapters on the concept of sovereignty. Chicago: The University of Chicago Press.

TANNENWALD, Nina. 2007. The Nuclear Taboo: The United States and the Non-Use of Nuclear Weapons Since 1945. Cambridge: Cambridge University Press.

TODOROV, Tzvetan. 2010. The Fear of Barbarians. Chicago: The University of Chicago Press.

Recebido em: 27 abril 2015

Aceito em: 22 junho 2015 